\title{
IDEAS E INTERESES: EL PROYECTO DE UNA COMUNIDAD IBEROAMERICANA DE NACIONES.
}

\author{
Juan Gabriel Valdes (*)
}

\section{ENTRE LOS AFECTOS Y LOS INTERESES.}

Ha sido el gran Ministro español Francisco Fernández Ordoñez, quién ha dicho que lo más importante de la próxima cumbre iberoamericana es la reunión misma de los veintitrés jefes de Estado y de gobierno que conforman "la familia" americana y europea de tradiciones comunes. De lo que se deriva que, como en toda reunión de familia, no son las normas previas, ni el afán acendrado de pulir textos, ni emitir grandes proclamas lo que los reúne, sino la contemplación de los comunes valores y la sensación compartida que si tan grande es el patrimonio cultural compartido, grande también puede ser la red de actividades y la acumulación de iniciativas que incrementen la presencia de esta comunidad en el mundo internacional del nuevo siglo.

La reflexión, valedera como es, encierra sin embargo una paradoja. Son tantos los factores históricos y culturales que nos reúnen, que resulta difícil explicar que hayan debido transcurrir siglos para que estos encuentros tuviesen lugar. En efecto, más allá de la propia conmemoración del Quinto Centenario del Descubrimiento de América, son muchos los factores de todo tipo que hayan debido concurrir para que ellas pudieran finalmente realizarse. Sin embargo, las cumbres iberoamericanas y su proyección futura, aparecen todavía hoy, como el esbozo frágil y esquemático de una situación asociativa con la fluidez política suficiente como para admitir, entre una definitiva consolidación y aquel languidecimiento que presagia el fracaso, toda clase de expectativas. La expresión más evidente de esta situación es que la reflexión sobre nuestro pasado, posee un amplio y documentado campo sobre el cual es posible la construcción de voluminosos discursos, mientras que el análisis de su proyección futura, requiere abrir camino en forma prudente y medida a iniciativas específicas que establezcan las bases -o si se permite un símil naútico- los astilleros sobre los cuales construir la nave común. La dimensión y la calidad de la voluntad colectiva determinará luego, si ella es capaz de navegar. En este sentido, la relación iberoamericana aparece como una especial sintonía que no reemplaza, ni menos aún suprime las instancias de coordinaciòn y acción internacional construídos con tanta dificultad entre latinoamericanos, pero que establece una frecuencia en la que ciertos temas -los del desarrollo principalmente, y los del desarrollo en democracia más especialmente- pueden ser debatidos.

Porque instalados como estamos en las postrimerías de la modernidad, la conmemoración del pasado es una audacia, no porque divida, sino porque no interesa a demasiada gente. En realidad, sin las cumbres de Guadalajara y de Madrid, sin la propuesta que éstas conllevan, la conmemoración del Quinto Centenario se habría diluido en un corto plazo. Al contrario, la sola promesa de concertación que las cumbres encierran, permite que la mayor riqueza de la memoria, que es la lengua, adquiera al menos la oportunidad de dotarse de voluntad política. Y es en el desarrollo de una voluntad política común donde radica el futuro que puede tener la comunidad iberoamericana de naciones. Sin ella, su historia será breve.

$\mathrm{Al}$ aventurar entonces algunas reflexiones sobre sus perspectivas conviene explorar someramente si la voluntad política que se expresa en la declaración de Guadalajara y en la decisión de continuar con la celebración de los encuentros de jefes de Estado y gobiernos iberoamericanos se instala verdaderamente en intereses reales tanto de las naciones latinoamericanas como de aquellas europeas que forman parte de lo que se ha dado en caracterizar -en expresión que a más de afecto denota prudencia como "la familia iberoamericana". Si la simple reiteración de los afectos no es suficiente para la constitución de una voluntad iberoamericana, se hace necesario descubrir e identificar los intereses comunes, intentar una lectura racional de las oportunidades y los riesgos compartidos, formular una comunidad de propuestas del Sur europeo y americano. Y ese camino, que no es breve, pero es grande y enormemente provisorio, requerirá de la conjunción de la voluntad y la inteligencia de muchos iberoamericanos.

\section{LAS CONDICIONES DE UNA CONCERTACION.}

Hemos mencionado antes que han debido concurrir una cantidad de factores para hacer posible la realización de las cumbres iberoamericanas. La coincidencia de las conmemoraciones del Quinto Centenario con cambios fundamentales en las condiciones políticas y económicas de la mayoría de los actores involucrados, así como con acontecimientos de gran trascendencia en el sistema internacional, ha sido determinante para que las reuniones de Jefes de Estado hayan podido verificarse. Sin ella, las cumbres iberoamericanas, acordadas ahora hasta 1994, no habrían pasado probablemente de una sola, la conmemorativa de 1992, y esa única, habría tenido un carácter retórico y difícilmente repetible. Pero, sobre todo, me parece necesario subrayar que es en estos cambios donde se encuentran las claves con las que explorar los intereses compartidos que darán susten-

(*) Embajador de Chile en España 
to a las cumbres futuras y en general al proyecto de una comunidad iberoamericana de naciones. ¿Cuáles han sido estos cambios?.

El primer factor en importancia ha sido la democratización del continente americano. Es evidente que sin los cambios políticos ocurridos en nuestra región a fines de la década pasada, habría sido imposible plantearse siquiera la construcción de aquel espacio que el Presidente González denomina tan apropiadamente como "una estructura de complicidades" entre los países iberoamericanos. Con toda la precariedad e insuficiencia que la democracia política tiene aún en nuestro continente, incluyendo la triste recurrencia de intentonas autoritarias, asonadas, golpes y autogolpes, me parece posible afirmar que el costo de la recaída autoritaria es hoy mayor que en el pasado, y que los principales actores sociales y políticos de la región, incluídos los militares, han comprendido que la democracia constituye un requisito de funcionamiento político y económico indispensable para un esquema de desarrollo basado en la inserción creciente en el sistema internacional.

Es evidente que la recuperación de la democracia en América Latina establece el marco para la realización de los encuentros iberoamericanos. Difícilmente ellos podrían haberse realizado en un cuadro de dictaduras y dictadores militares. La persistencia en la región de gobiernos no democráticos constituye hoy, por el contrario, un aliciente para que las cumbres y cada uno de sus participantes manifieste su vocación de respeto por el estado de derecho y por el respeto a las formas de la democracia política y la vigencia de los derechos humanos y civiles.

Cabe anotar en seguida la transformación copernicana de los criterios de organización de las economías en nuestra región. El tema es ya suficientemente conocido: una parte muy importante de los países de América Latina han apostado por una modernización de sus economías, que incluye la apertura a la competencia internacional, la mantención de los equilibrios macroeconómicos, la reducción del tamaño del Estado, las privatizaciones y el impulso a una clase empresarial, que se desea más dinámica y menos protegida. El clima económico actual en varios países de la región ha probado ser suficientemente atractivo como para atraer volúmenes importantes de inversión extranjera norteamericana y europea. Hoy son muchas las autoridades españolas que reconocen que más que en los países del Este europeo, es en Chile, México o Argentina, donde más probablemente se desarrollará la necesaria internacionalización de la clase empresarial española. El incremento del comercio y la inversión española, y la creación de "joint ventures" con empresas de América Latina puede ser en este marco el sustento material necesario para consolidar el diálogo político y cultural de nuestras futuras cumbres iberoamericanas.

De todo esto ha aprovechado el proyecto de acercamiento de América Latina y España y Portugal. Sin la modernización actual de algunas de las economías de América Latina, la dimensión social del proyecto habría estado limitado a los aspectos culturales, capaces de generar identidad, pero no los intereses como para proyectar y mantener una concertación internacional.
También ha posibilitado el desarrollo de las cumbres y de su proyecto futuro el que exista hoy en América Latina una conciencia bastante generalizada de la necesidad de impulsar una corrección de los factores de inequidad que hacen sus sociedades duales, a veces hasta el extremo de la esquizofrenia social. Si las necesidades de impulsar la educación y el desarrollo social han conformado uno de los motivos centrales del debate de los jefes de Estado y de gobierno iberoamericanos, las cumbres pueden también constituirse en un espacio de reflexión sobre las formas de conciliar las exigencias de la economía y la democracia en un marco de estrechez. Como se sabe, las "economías sanas" en sociedades enfermas de miseria sólo existen por un tiempo en los informes oficiales de gobiernos desaprensivos.

Al mismo tiempo, los enormes sacrificios que han exigido y exigen las políticas de ajuste y la mantención del orden macroeconómico conseguido, requieren no sólo de un esfuerzo nacional en la lucha contra la marginalidad y la miseria, sino también de la responsabilidad y la honestidad de una clase política que pone en juego, en estos procesos, toda su credibilidad y legitimidad. Las cumbres de Jefes de Estado y de gobiernos podrían constituir igualmente, en un período de dificultades de la teoría democrática, un buen espacio de reflexión colectiva sobre las responsabilidades de las autoridades públicas y el valor permanente del ejercicio político.

Si la recuperación democrática establece la base de valores compartidos, las tendencias a la homogeneización de las políticas económicas latinoamericanas, su estabilización y ordenamiento en proyectos sucesivos y cada vez más audaces de integración y cooperación económica, genera a su vez un soporte para el entramado de relaciones económicas y comerciales del mundo iberoamericano. América Latina se organiza paulatinamente en bloques en los cuales prima hoy un sentido económico y comercial al que pronto se unirán consideraciones políticas y estratégicas. Pero al mismo tiempo, la región se hace cada vez más disímil, sus países parecen diferenciarse cada vez más. Como lo indican los informes de la CEPAL y del ILPES, las diferencias en el desarrollo económico y social de los países de América Latina aumentan en vez de disminuir. En este contexto, en el que la participación en instancias de coordinación regional se hará cada vez más necesaria, la progresiva estructuración de una comunidad iberoamericana será de importancia para recalcar la necesaria cohesión de países que en un contexto de disparadas diferencias económicas podían extraviar el sentido de identidad común.

Los cambios sin embargo, no han ocurrido sólo en América Latina. Las cumbres iberoamericanas son posibles debido de manera muy principal a la transformación extraordinaria de España. Su admirable transición a la democracia y el formidable proceso de modernización económica y social que ha experimentado durante la última década, ha producido un impacto sustancial en las élites políticas y culturales de la región latinoamericana. El redescubrimiento de España por los latinoamericanos ha precedido por algunos años al Quinto Centenario y ha sido el fermento sobre el cual el interés mutuo expresado en las 
cumbres de Jefes de Estado ha podido asentarse. Una España democrática, actor vigoroso en la Comunidad Europea -con la que muchos de los países latinoamericanos mantienen sus principales vínculos comerciales- permite por fin, en nuestro mundo latinoamericano, la conjunción de los afectos ancestrales con los intereses concretos.

\section{LOS CAMBIOS INTERNACIONALES.}

A estas transformaciones en los actores, hay que agregar las enormes modificaciones que han ocurrido en el sistema internacional en el curso de los años recientes. El fin de la guerra fría ha sido en la práctica una condición de existencia para la constitución del clima que preside las reuniones iberoamericanas. Ellas serían difíciles de imaginar, en un cuadro político como el que caracterizó el fin de los años sesenta y el inicio de los setenta, cuando en casi todo el continente latinoamericano se registraba una intervención abierta de ambas potencias y los movimientos políticos locales se alineaban en posturas ideológicas dictadas por lo que se conocía como el Este o el Oeste. De haberse planteado entonces, las reuniones no habrían podido orientarse por una reflexión sobre las oportunidades futuras que abre la identidad común iberoamericana, sino habrían estado marcadas por el recelo y la tensión producida por las múltiples guerras internas, los consiguientes movimientos insurreccionales y operativos militares, las violaciones a los Derechos Humanos, los rasgos de ilegitimidad de algunos gobiernos y el acostumbrado celo de los Estados Unidos ante cualquier iniciativa que le separara del control directo de una operación latinoamericana que entendió casi siempre como un tema militar.

Hoy, en cambio, el fenómeno que acompaña de manera más visible la constitución de bloques internos en América Latina es el acercamiento de cada país y de la región en su conjunto a los Estados Unidos. En efecto, jamás se ha registrado, en este siglo, un período de mayor buena voluntad de los latinoamericanos hacia sus vecinos del norte, lo que se expresa no sólo en el desvanecimiento o marginalización de las ideologías "anti-imperialistas", sino en las múltiples propuestas para acercar e integrar las economías de cada país con la norteamericana. No puede dejar de observarse, al mismo tiempo, que la respuesta de los Estados Unidos a esta actitud latinoamericana, ha sido por decir lo menos, escasa, pero también, que como ironía de la historia, el acercamiento latinoamericano al Norte se ha encontrado con ese país en condiciones de dificultad nunca vistas. Es este contexto el que permite que la actividad política española y más en general europea en nuestra región sea recibida en clave de cooperación y no de intromisión por un Estados Unidos que hasta hace una década insinuaba a menudo los ecos de la doctrina Monroe ante cualquier incursión europea en los conflictos internos latinoamericanos.

\section{EL PERFILAMIENTO DE LOS INTERESES.}

Si éstos son los procesos que han permitido las reuniones de Guadalajara y Madrid, y más en general, el clima positi- vo con el que se observan las iniciativas iberoamericanas, ¿qué tipo de intereses parecen derivarse para nuestros países y para España y cuál podría ser su magnitud?.

En términos de los procesos globales y continuando de algún modo la reflexión anterior, la pregunta principal se refiere a la dinámica que introduce una proyección de las cumbres iberoamericanas y más en general, del diálogo iberoamericano en las relaciones orbitales de sus partes constitutivas: las de América Latina con los Estados Unidos y las de España y Portugal con Europa. Desde esta perspectiva, lo que hemos llamado la sintonía iberoamericana, cuya principal pero no única expresión está constituída por las cumbres de Jefes de Estado y de gobierno, abre una vía eventual para la generación de equilibrios que permitan que la relación de los latinoamericanos con los Estados Unidos, buena y estrecha como debe ser, no adquiera características sofocantes. El punto no debe ser exagerado sin embargo. Lo que interesa es destacar que, más allá de las múltiples instancias de integración latinoamericana, cada una de las cuales contiene significaciones importantes de identidad regional, la afirmación de una identidad más amplia iberoamericana es en sí misma una significación política valiosa, y sirve como un factor de equilibrio ante una internacionalización que atrae compleja y a veces recíprocamente al Sur de América hacia el Norte con la fuerza de un fenómeno geológico.

Este interés delimitativo de dependencias tiene sin embargo una acepción positiva. Las relaciones de América Latina con los Estados Unidos y con España, y de este país con los Estados Unidos respecto de América Latina, -que son en definitiva las principales que tendrá al márgen de la Comunidad Europea- no son mutuamente excluyentes ni deben ser vistas necesariamente en términos competitivos. La constitución de triángulos de cooperación política entre países latinoamericanos, España y los Estados Unidos han probado ser de mucha utilidad en la solución de difíciles problemas de pacificación en la región latinoamericana. El triángulo de cooperación estadounidense, español, latinoamericano constituye así un elemento valioso de acción internacional que sería conveniente extender más allá de la acción estatal, al campo empresarial, al de la investigación científica, y muy especialmente en el momento actual, al campo del análisis proyectivo del desarrollo latinoamericano, área en la cual la interacción de norteamericanos y latinoamericanos en Universidades y centros especializados se vería enriquecida por la perspectiva española y otorgaría a la vez a los centros de reflexión y análisis internacional de España, el acceso a niveles de especialización en la región que aún no alcanzan.

Una reflexión semejante puede realizarse respecto de España y Portugal. En la Europa de fin de siglo, el sur de Europa, y muy especialmente España, deberán enfrentar desafíos de una enorme magnitud. Los esfuerzos por impedir que el eje comunitario se traslade de manera cada vez más pronunciada al norte, trás el ingreso de los países de la EFTA, y la compleja dinámica que establece la relación de Alemania con los paìses desgajados de la ex-Unión Soviética, requerirán de un acumulación de influencia internacional para el que las debilitades políticas de Francia e 
Italia no presagian nada bueno. EL rol de España será sin embargo protagónico. Trás el tratado de Maastricht, la agenda de la construcción comunitaria establece como una prioridad para España, el tema de la cohesión, en el que necesariamente deberá adoptar frente al Norte europeo, una posición de protagonismo. Su rol se extenderá también en forma principal al Magreb y de la inmigración africana, lo que implica que España se verá también necesariamente ocupando una posición protagónica en el debate Norte-Sur. De algún modo, esta situación pondrá a España en un arco de problemas similares a los que Alemania deberá enfrentar ante la Europa del Este. Con todas sus diferencias de potencialidad, los dos países constituyen llaves para lo que Europa podrá realizar al abrirse el próximo siglo.

En este cuadro europeo, que parece cada vez más complicado por turbulencias cuyos inicios apenas se entienden y cuyas consecuencias son imposibles de imaginar, el nicho iberoamericano puede ser para España bastante más que un solar familiar. Hemos mencionado ya las oportunidades de internacionalización del capital español que la región latinoamericana abre a España. Debe agregarse igualmente la experiencia que España ha logrado en América Latina en programas de cooperación internacional y más generalmente en políticas de desarrollo.

La mundialización de la economía y la tecnología y la combinación de crecimiento con equidad, parecen ser hoy las fórmulas que pueden detener la catastrófica combinación de la destrucción ecológica y la producción de miseria a escala global. En ese contexto, la inversión productiva externa, en combinación con otros factores como la transferencia tecnológica y los programas de cooperación, será entendida crecientemente como un factor constitutivo del proceso de desarrollo. España encuentra en su relación con América Latina la posibilidad de ejercitar una experiencia de desarrollo que adquiere relevancia frente al tema del Magreb y de su relación más general con Europa.

La idea de una España como puente de América Latina con la Comunidad Europea ha sido mencionada en demasía y tiene sin duda un aspecto de cliché poco atractivo para un análisis. Como ya se ha dicho, las reuniones del Grupo de Río con la CEE y otras instancias de diálogo latinoamericano-comunitario tienen plena vigencia y se constituirán a menudo en espacios de resolución de problemas puntuales económicos, comerciales y políticos.
El rol de España en la Comunidad comienza a adquirir sin embargo para los países latinoamericanos una gravitación cada vez mayor. Ha sido precisamente aquella sintonía propia de la relación latinoamericana con España la que ha permitido introducir temas de relevancia para la región tales como el de los créditos para América Latina del Banco Europeo de Inversiones, o el de ciertos avances en los programas de cooperación. Lo más valioso de estos pasos, que no siempre serán consonantes, ya que es simplemente normal que en varios campos se verifiquen intereses divergentes, es que ellos pueden ir conformando un concepto iberoamericano del desarrollo social, un concepto compartido de la necesidad y de la forma como América Latina debe enfrentar la cuestión de su propio desarrollo en cooperación con Europa y otros actores internacionales. Es allí donde la llamada complicidad adquiere su más pleno sentido.

\section{UNA ESTRUCTURA DE COMPLICIDADES.}

La próxima cumbre de Madrid se ha propuesto ratificar la declaración de principios comunes elaborada en Guadalajara y aprobar algunos proyectos vinculados al desarrollo latinoamericano y la cooperación iberoamericana especialmente en el terreno de la educación. Pienso que el carácter puntual y medido de dichas iniciativas debe ser puesto contra el trasfondo que hemos muy someramente descrito anteriormente. La elección de la educación como el tema principal, responde perfectamente a la necesidad primordial por hoy, de dar un impulso a la complicidad iberoamericana y luego canalizarla hacia los espacios más amplios e imprevisibles de la sociedad civil.

La proyección futura de las cumbres iberoamericanas requiere de una articulación de una sociedad civil crecientemente común, que lleve un diálogo de cooperación y concertación con los gobiernos. Las redes educacionales, empresariales, universitarias, juveniles, sindicales, construídas en el marco de la afinidad iberoamericana serán la única base real de expresión de intereses que vigorice la iniciativa política ya asumida por los Jefes de Estado. De este modo, la cooperación entre gobiernos es en este sentido un punto básico de partida, pero es en la generación de un entramado o estructura de complicidad entre las élites españolas y latinoamericanas donde se halla el objetivo de largo plazo. Sin este objetivo, la solidez de la asociación deseada será siempre precaria.

\section{RESUMEN}

Las cumbres de Guadalajara y de Madrid permiten que la riqueza cultural compartida tenga la oportunidad de dotarse de voluntad política común. Los intereses compartidos que darán sustento a las cumbres iberoamericanas futuras son la democracia, las tendencias a la homogeneización de las políticas económicas latinoamericanas, su estabilización y ordenamiento en proyectos sucesivos y cada vez más audaces de integración y cooperación económica.

\section{ABSTRACT}

The Guadalajara and Madrid summits allow that shared cultural richness has the opportunity to express a common political desire. The shared interests which will make possible next summits are democracy, tendencies toward homogenized Latin-American economic policies, its stabilization and ordaining in successive projects of economic cooperation and integrations more and more audacious. 